\title{
Hepatitis B Virus-related Liver Disease Burden in South Asia
}

\author{
Abhijit Chowdhury \\ Department of Hepatology, School of Digestive and Liver Diseases, Institute of Post Graduate Medical Education and Research \\ Kolkata, West Bengal, India
}

Correspondence: Abhijit Chowdhury, Professor and Head, Division of Hepatology, School of Digestive and Liver Diseases Institute of Post Graduate Medical Education and Research, Kolkata, West Bengal, India, e-mail: achowdhury2002@yahoo.co.in

\section{ABSTRACT}

Hepatitis B is major health concern globally, specially in the Asia-Pacific region. The virus results in countless premature mortalities and greater number of morbidities. While the scientific community is more focused toward HBV-related liver disease burden, the toll of this virus on our economies remain largely undermine. Proper planning and active participation of the government machinery and decision makers are vital to the best utilization of resources of our resource-constrained countries for the implementing best possible measures against hepatitis B.

Keywords: Hepatitis B, Disease severity, Economic impact.

\section{INTRODUCTION}

Hepatitis B virus infection is a public health priority whose significance, unfortunately, is yet to be properly perceived by health planners of South Asian countries. The factors responsible for this relative omnivalence and indifference of the policy makers are manifold. Health care resources and finances in these areas have still to take care of the continuing painfully high burden of malnutrition and traditional communicable diseases, like diarrhea, respiratory infections, tuberculosis and malaria. While the mortality and morbidity caused by these age old maladies of underdevelopment are still too high to be complacent, it is high time we take note of a whole new cluster of diseases related to changes in lifestyle and chronic infections that are emerging.

Among the chronic infections that are significant, hepatitis B virus is topping the list in view of its fairly high prevalence in the general population of South Asia, the spectrum of derangements in liver dysfunction that it causes including cirrhosis of the liver and hepatocellular carcinoma as well, the fact that all these problems are very much preventable by a vaccine. It is to be noted that although hepatitis $\mathrm{B}$ virus has long been considered to be predominantly an Asian problem, South Asia failed to figure in global concern for control of hepatitis $\mathrm{B} .^{1,2}$ A painful lack of research data on different aspects of hepatitis Brelated liver diseases in these areas-population prevalence, natural history, molecular biological characteristics and therapy outcome-are crucial factors in this scenario. Thus, while the planners, policy makers and politicians look forward to the glimpses from scientific information, the research community cannot deny its responsibility in not being able to rise up to the needs of the situation. Its heartening that changes are evident here and literature is getting enriched through information on hepatitis B from India and Bangladesh.

Hepatitis B infection becomes evident and come to clinical attention in primarily four clinical settings: Inactive HBV carrier state, chronic hepatitis, cirrhosis of liver and its sequel and finally, hepatocellular carcinoma. Importantly, this sojourn from inactive infection to hepatocellular carcinoma is very often silent clinically and patients frequently come to clinical attention too late in the course. Lack of awareness among the people as well as the profession about the subclinical nature of progressive hepatitis B, widespread ignorance, poverty, illiteracy impeding access to medicare, nonavailability of vaccines in public health care delivery system are some of the many issues that are productive of this situation. Thus, hepatitis B, as perceived in South Asian countries, is not only a medicare issue but also a reflection of the prevailing social and public health arrangements in the society (Box 1).

Burden of disease has many dimensions and is most important in health planning (Fig. 1).

Liver diseases cause morbidity and mortality in two primary clinical forms. This can either be acute hepatitismost of which are mild and self-limiting. Only a small minority of these need hospitalization and death is uncommon. However, acute liver failure can occur in a few with a high mortality, in the absence of liver transplantation. In some others, a protracted clinical illness can delay 


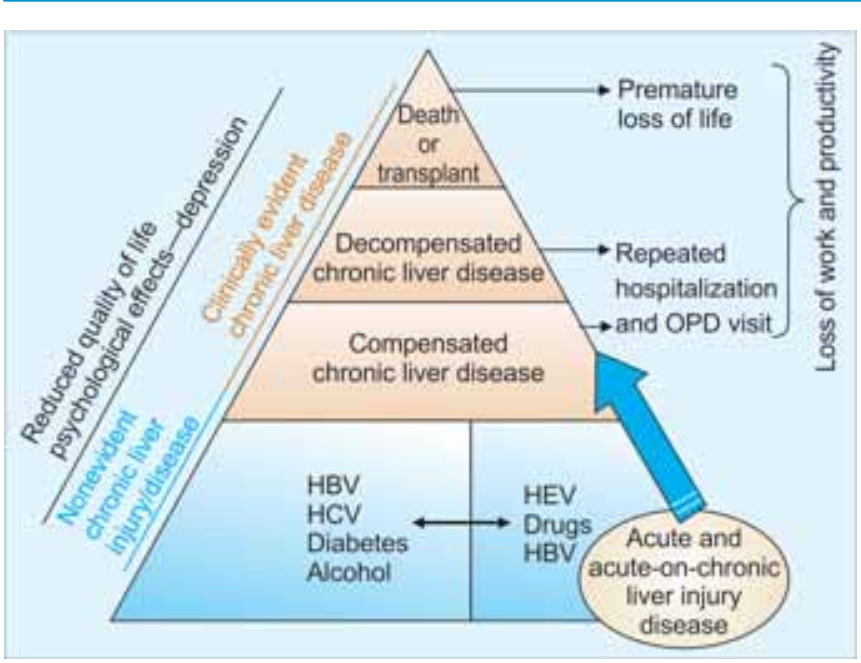

Fig. 1: Different clinical syndromes in liver disease and healthcare burden: The disease burden matrix in liver disease

recovery, result in loss of work capacity and so is important socioeconomically. ${ }^{3,4}$ More important from the viewpoint of health care policy making, are the chronic liver diseasescirrhosis of liver and hepatocellular carcinoma. They have a prolonged, progressive and often an indolent course interspersed by acute clinical events that necessitate hospitalizations. While impaired quality of life and loss of work accompany such prolonged unwell being, end stage chronic liver diseases are important cause of mortality, frequently premature. This can occur either during one of the acute complications, such as variceal bleeding. Otherwise in a progressive downhill course, ascites, renal dysfunction, encephalopathy, infections, etc. can all be present in different magnitudes, resulting in the need of frequent curative care support, financial losses and finally death, in the absence of liver transplantation. According to World Health Organization estimates, cirrhosis of liver and hepatocellular carcinoma caused 7,83,000 and 6,19,000 deaths worldwide in 2004. Taken together, these conditions account for $2.5 \%$ of the worldwide mortality figures. Despite the apparent miniature appearance of the numerical value mentioned, in an era of personalized health care and when right to have access to just health care is being given credence in Indian society and politics—it is high time that organized research is undertaken on liver disease burden in the country and useful data generated for planning. Side by side, there had been major changes in scientific approach to liver disease over the last one or two decades. Approach to assessment of liver disease is much more objective now. Cirrhosis of liver is very much treatable with an intent to regression if not reversal of pathology. Antivirals are changing the face of even advanced decompensated HBV related liver disease and can delay/abort the need for transplantation. Similar change is evident in other causes of liver disease, including the possibility that focused antifibrotics will soon become available.

\section{Box 1}

\section{Elements in liver disease burden estimation}

- Prevalence and incidence of the disease

- Morbidity-loss of work, impairment of quality of life

- Mortality-death, premature loss of productivity

- Health care utilization trends-frequency of hospitalization, outpatient visit, level of care (primary/secondary/tertiary)

- Economic impact-cost of care, including loss of productivity, due to loss of work.

While all these changes are visible and palpable, liver disease is yet to achieve a priority with the planners of the country and is a subject of discussion in professional societies alone. This is evident in the casual fashion in which the HBV immunization program is being implemented in the region, much lagging behind a global tide in its favor.

There are several good quality population prevalence studies on $\mathrm{HBV}$ in both India and Bangladesh. ${ }^{5-9}$ Conservative estimates indicate that the prevalence of $\mathrm{HBV}$ in India to be at least $3 \%$, while it is much higher in Bangladesh (7-10\%). There are regional differences in HBV scenarioboth within country and between countries. Thus, while HBV prevalence is high in Bangladesh (7-10\%), it is much lower in West Bengal (3\%). Within India, Arunachal Pradesh has a high prevalence (7\%), while Northern states have a lower prevalence (1-2\%). Pakistan also has a lower prevalence of hepatitis B infection, although the prevalence of hepatitis C virus infection in Punjab state of India and Pakistan is high. Thus, possible cultural and ethnic determinants may be operative in discerning the way the hepatitis viruses evolve in the region. In addition, the outcome of infection is influenced by genotype. Thus, genotype $\mathrm{C}$ infection - the one associated with hepatocellular cancer-is seen more frequently in Bangladesh and Eastern part of India, as compared with rest of South Asiawhere genotype D and A predominate. There are several other features of HBV infection, which can be dissected by planned cross country and regional studies. While these are likely to be the most useful for burden reduction will be organized implementation of HBV immunization program across the region. We are lagging behind significantly compared with global efforts. We should not delay it further.

\section{REFERENCES}

1. Williams R. Global challenges in liver disease. Hepatology 2006;44:521-26.

2. Kao JH, Chen DS. Global control of hepatitis B virus infection. Lancet Infect Dis 2002;2:395-403.

3. Lavanchy D. Hepatitis B virus epidemiology, disease burden, treatment, and current and emerging prevention and control measures. J Viral Hepat 2004;11:97-107.

4. Ezzati M, Lopez AD, Rodgers A, Vander HS, Murray CJ. Selected major risk factors and global and regional burden of disease. Lancet 2002;360:1347-60. 
5. Acharya SK, Madan K, Dattagupta S, Panda SK. Viral hepatitis in India. National Med Journal of India 2006;19:203-17.

6. Chan CY, Lee SD, Lo KJ. Legend of hepatitis B vaccination: The Taiwan experience. J Gastroenterol Hepatol 2004;19: 121-26.

7. Mahtab MA, Rahman S, Karim MF, Khan M, Foster G, Solaiman S, et al. Epidemiology of hepatitis B virus in Bangladeshi general population. Hepatobiliary Pancreatic Disease International 2008;7(6);595-600.
8. Mahtab MA, Kumar SI, Rahman S, Kamal M, Khan M, Aggarwal R. Hepatitis B virus genotypes amongst chronically infected patients in a tertiary care hospital in Bangladesh. Indian J Gastroenterol 2006;25(4):219-21.

9. Chowdhury A, Santra A, Chakravorty R, Banerji A, Pal S, Dhali GK, et al. Community based epidemiology of hepatitis B virus infection in West Bengal, India. Prevalence of $\mathrm{HBeAg}$ negative infections and associated viral variants. Journal of Gastroenterol Hepatol 2005;20(11):1712-20. 